\title{
La autofiguración en Hombre de la esquina rosada, de Jorge Luis Borges.
}

\section{Self-figuration in El hombre de la esquina rosada by Jorge Luis Borges.}

DOI: 10.32870/sincronia.axxv.n80.17b21

\author{
Benjamin Aguilar Sandín \\ Universidad Autónoma del Estado de Morelos (MÉXICO)
}

CE: aguilarsandin@gmail.com / ORCID: 0000-0003-0758-6262

Esta obra está bajo una Licencia Creative Commons Atribución-NoComercial 4.0 Internacional

Recibido: 31/03/2021

Revisado: $14 / 05 / 2021$

Aprobado: 17/06/2021

\section{RESUMEN}

En este artículo se analizará el cuento Hombre de la esquina rosada del escritor argentino Jorge Luis Borges. El objetivo es establecer la relación entre la imagen textual elaborada por Borges en el cuento y el concepto de “autofiguración” propuesto por el crítico José Amícola, que lo retoma de la crítica Sylvia Molloy. Para realizar este análisis, en primer lugar, se hará un breve recorrido histórico, sobre todo desde la aparición, en el siglo XVIII, de la autobiografía como género, hasta la consolidación de los escritos autobiográficos en Europa y Argentina en el siglo XIX, y cómo esta relación histórica ayudará también a analizar el concepto de autofiguración en el caso específico de Borges. Posteriormente se abordará la relación de Borges con los relatos de cuchilleros, la relación de los relatos de cuchilleros en la tradición literaria $y$, finalmente, la autofiguración del escritor argentino en el cuento "Hombre de la esquina rosada". Para analizar los elementos significativos de los relatos de cuchilleros en Borges e identificar algunos elementos de dichos relatos que podrían coadyuvar en su autofiguración se utilizarán también la teoría sobre Borges y la gauchesca desarrollada por el crítico Jesús Dávila. 
Palabras claves: Autofiguración. Borges. Autobiografía. Relato de cuchilleros. Escrituras del yo. Literatura hispanoamericana.

\section{ABSTRACT}

This work will analyze the short story Hombre de la esquina rosada by Argentine writer Jorge Luis Borges, in order to establish a relationship between the textual image created by Borges and the concept of Self-Figuration proposed by critic José Amícola (who builds upon the work of critic Sylvia Molloy). In order to further this analysis a brief historical review will be made, particularly focused on the appearance of Autobiography as a genre in the Eighteenth Century and its later consolidation in both Europe and Argentina during the Nineteenth Century. This historical relationship will be used to help analyze the concept of SelfFiguration in the specific case of Borges. Subsequently, this analysis will consider Borges' relationship with cutlers' stories, the relationship of these stories with larger literary tradition and, finally, the Argentine author's Self-Figuration in the tale "Man on the Pink Corner." Commentary from theorist Jesus Davila will also be used to analyze significant features of Borges' cutler's stories and identify elements of said stories which could contribute to Borges' Self-Figuration.

Keywords: Self-figuration. Borges. Autobiography. Cutlers stories. Writings of the self. Spanish-American literature.

\section{Introducción}

El estudio de la autobiografía y otros textos relacionados a la constitución del yo tales como diarios íntimos, cartas y, más recientemente, los relatos autoficcionales, han llamado la atención de la crítica y la teoría literaria prácticamente desde que la autobiografía apareció en Europa bajo la figura de Juan Jacobo Rousseau, aunque ya desde la época clásica grecolatina se podían percibir algunos referentes imprescindibles para la consolidación del género con textos como las Confesiones de San Agustín (Amícola, 2007) título que emularía el propio Rousseau para dar vida a esta constitución del yo textual moderno.

De manera posterior se ha podido ver el ejercicio del género autobiográfico no solo en Europa sino también en América, donde ha tenido un desarrollo muy particular. Con su punto de 
eclosión en el siglo XIX la autobiografía se ha convertido en un referente importante para la construcción de conceptos fundamentales en la consolidación del estado moderno tales como el concepto de identidad nacional, y esta relación se puede hacer evidente, por ejemplo, en el caso de los próceres que participan activamente en la independencia de las colonias españolas en América, de tal manera que en estos países nacientes como fue el caso de Argentina, las autobiografías de personajes históricos como Esteban Echeverría o Domingo Faustino Sarmiento ayudarían a conformar, con la historia de su vida contada en primera persona, una relación que trataría de hacerse íntima para los lectores de la época con la idea de yo y la idea de nación (Prieto, 1966).

En el siglo XX, las posiciones del yo se modifican y pluralizan. Desde las primeras décadas, los escritores problematizaron al yo y su configuración autobiográfica en los términos en que se concibió en el siglo XIX. Esto no significa que se hayan eliminado las configuraciones del yo autoral, sino que cambió la concepción misma de yo. El objetivo de este artículo es explorar, específicamente en el cuento "El hombre de la esquina rosada", cómo Borges construye una figura de sí mismo. Se parte de la idea de que su aproximación es diametralmente opuesta al modelo escritural autobiográfico, y se examina cómo la figura de sí mismo puede tener relación con la postura que rechaza la idea de un yo monolítico, optando por la constitución de un yo múltiple. Particularmente se utilizará la propuesta de José Amícola sobre la autofiguración para observar los constitutivos de la construcción textual de la figura de autor en el cuento mencionado.

\section{Orígenes de la autobiografía como género}

\section{Rousseau, la Autobiografía como género establecido y la constitución del yo}

Un antecedente directo de lo que representará la autobiografía ${ }^{1}$ como género y, por lo tanto, la constitución del yo dentro del relato autobiográfico es la aparición de los Essays de Montaigne, que adoptan dos modos que posteriormente serán recuperados por Rousseau en sus "confesiones". En

\footnotetext{
${ }^{1}$ Ni Vico ni Rousseau habrían utilizado el término, que es una acuñación inglesa que se hace, según Olney (1980), en 1807 o, de acuerdo con Bruss (1976), en 1809. Antes de estas fechas tentativas, el término más cercano para designar este fenómeno era el de "Periautografía", utilizado en 1700 por el editor de Vico (Sturrock, 1993, p.106).
} 
los Essays se articula por primera vez el yo en primera persona, que es un yo que se construye a partir de la idea de "sinceridad", siendo Rousseau heredero directo de esta tradición, "De este modo las complejidades, contradicciones y aberraciones de la propia persona no causan vacilación o repugnancia, sino sorpresa" (Olney, 1980, p.33) Por primera vez en el texto se conforman "todo tipo de desviaciones mentales que afectan a la vida de la intelectualidad y que es vista ahora como un conjunto de excepción" (Amícola, 2007, p.73).

Rousseau plantea un modo de pensar que asumirá matices diametralmente opuestos a las máximas de la llustración, y de esta manera la vieja frase "pienso, luego existo" que condensará parte de este modo de conocer la realidad, será suplantada ahora por la "Dado que soy yo el que paso la vida conmigo, debo conocerme" (Starbinski, 1971, p. 222) que inaugura el pensamiento romántico burgués.

Rousseau funda, con "Las confesiones", un modo de percibir la realidad, un modelo de interiorización que, posteriormente, se irá repitiendo tanto en el modelo autobiográfico como en la narrativa de autores tales como Jane Austen, que, recuperando las pautas de Rousseau, también realizará una crítica aguda de la sociedad burguesa de su tiempo (Amícola, 2007, p.77) pero desde el relato ficcional.

Además, Rousseau hereda una forma de constitución del yo que se repetirá en numerosos textos posteriores. Para el filósofo ginebrino el hecho de contar lo íntimo y lo cotidiano resulta ante todo una proeza, puesto que, al intentar cobrar en sí mismo un sentido de totalidad, se cuestionará también por los mecanismos narrativos en esta nueva e íntima constitución de un yo que percibe el mundo. Rousseau abogará entonces por reconstituir un nuevo sentido, una nueva manera de contar que tiene la impresión de el hecho de contar la vida misma a través de lo cotidiano. De acuerdo con Starobinski (1971): "En definitiva, el problema radicaba en cómo elegir los hechos nimios, cómo contar el instante minúsculo que ha dejado, sin embargo, una marca de conciencia" (p.229-230).

Frente a esta problemática existirá otra no menos imprescindible, que tiene que ver con la pregunta de cómo debe elegirse el momento en el cuál comenzará a representarse la propia vida, 
puesto que, según Starobinski (1971), Rousseau es consciente de que cualquier momento de la vida que se elija para contar es arbitrario y, por lo tanto, el fluir temporal en el texto también lo es, por lo que la propia vida contada se vuelve una "fragmentación de los hechos vividos".

Amícola, por su parte, hará una crítica respecto a la postura de Starobinski, cuyo argumento central radicará en el hecho de que la tradición en el modo de narrar es históricamente no separable del momento en que se narra, y así:

Del mismo modo en que un novelista debe decidir en qué momento inicia su historia y cree hacerlo al ser original en esa selección de las experiencias de sus personajes, hay una tradición que marca en cada época y en cada sociedad cuáles son los hitos a tener en cuenta, a partir de inicios que se relacionan ya sea con hechos etnoculturales, como los ritos de pasaje, o ya sea con las tradiciones de los géneros discursivos, que ya han efectuado un recorte por sí mismos en la vida cotidiana de los miembros de una sociedad. (Amícola, 2007, p.79).

Para George Misch, en relación con lo dicho por Amícola, la Autobiografía será entonces un modelo y un modo de estar en el mundo, pero no solamente desde la contemplación más pura, sino más bien un "lanzarse a la marea, aunque con las armas de la escritura" (Amícola, 2007) para tratar de reflexionar individualmente sobre la experiencia en el mundo.

Del mismo modo, en la constitución de este yo autobiográfico, Rousseau, gran lector de los clásicos griegos y latinos, sentirá una especial predilección por autores como Plutarco y el texto De capienda ex inimicis utilitate (Cómo extraer provecho de los enemigos), y así, en la constitución de este yo, "el filósofo ginebrino es una figura ejemplar, pues en una actitud típicamente paranoica y estando convencido de que tenía enemigos por todos lados, actuó escriturariamente en consecuencia, especialmente en sus textos autobiográficos (Sturrock, 1993, p.49).

En la configuración de este yo, Rousseau utiliza mecanismos narrativos muy particulares, por ejemplo, puede llegar a hacer uso de un registro vernáculo del lenguaje en cuanto a cómo se refiere a otros tocando temas relacionados sobre todo con la sexualidad, pero, cuando se trata de abordar 
su propia sexualidad, es en extremo decoroso y mantiene un sumo cuidado hacia cómo representa sus experiencias sexuales (Lejeune, 2005, p.56) marcando nuevamente aquí una barrera entre el yo público, que es este Rousseau textual, y el yo privado, la figura del autor que escribe el texto.

Para Lejeune, "Las confesiones" representan un hito en el modo en que se configura la verdad en el texto, puesto que, Rousseau, al relatar las fechorías realizadas desde la infancia más tierna hasta la adolescencia, con particular interés en el episodio de la criada, donde, de manera flagrante, el joven Rousseau comete el robo de una cinta para después inculpar a la criada, de la cual está enamorado, y así realizar este acto de confesión varias décadas después, se pone en entredicho la manera en que Rousseau (y la mayoría de los textos autobiográficos) "trabajan con una economía de la disyunción, el desplazamiento y el asíndeton" (Amícola, 2007, p.83).

\section{Autobiografía en Hispanoamérica: El caso de la Autobiografía en el Río de La Plata y Adolfo Prieto} como antecedente del estudio de Autobiografía moderna

Uno de los teóricos más importantes del estudio de la autobiografía en Hispanoamérica y particularmente en Argentina es Adolfo Prieto, quien, en 1966 empieza a publicar, representa todo un hito en el estudio de la autobiografía, ya que comienza el debate en la cuestión de la figura autobiográfica incluso antes de que Lejeune problematizara el tema.

La intención de Prieto originalmente es borrar la línea de indeterminación que cubría todo el espectro de la autobiografía como género, ya que esta manifestación textual había sido muy popular en el Río de la Plata (Amícola, 2007, p.100) y no se le había prestado suficiente atención.

Prieto, para sustentar su teoría, cita a Misch, siguiendo esta idea de que "hay una ley general de formación de las grandes autobiografías, según la cual su desarrollo depende del grado de comprensión general que el autobiógrafo alcanza mediante su propia experiencia de vida" (Prieto, 1966, p.15). Esto tiene que ver, entonces, con que el autobiógrafo, más que contar la historia de su vida, cuenta su experiencia de vida, que no necesariamente corresponde a una narrativa lineal y cerrada. 
Dado que la autobiografía presupone una comprensión de la realidad del autobiógrafo, no es extraño que pueda, de la misma manera, "poseer la potencia necesaria para formar y transformar los hechos históricos" (Prieto, 1966). Para Misch la autobiografía estaría, en ese sentido, al mismo nivel que la poesía, puesto que ambas expresiones textuales, a pesar de tener pretensiones tan disímiles, narran la experiencia de "habitar" el mundo, con la diferencia de que, por razones obvias, la autobiografía sí tiene que buscar ante todo la facticidad.

Para Misch la autobiografía estaría ligada al reino de lo poético en una especie de “encasillamiento" del género (Amícola, 2007, p.101) atendiendo también, en sentido clásico, al Dichtung, que se relaciona, en alemán, con el sentido de lo puramente literario (Prieto, 1996, p.15)

De la misma manera, Misch establecerá una relación directa entre la configuración de este yo puramente autobiográfico con la Filosofía de Vida planteada a su vez por William Dilthey. Así, Amícola encontrará, siguiendo tanto a Prieto como a Pierre Bordieu, una línea de convergencia entre la biografía y la autobiografía modernas en la propuesta filosófica de la filosofía de vida (Bordieu, 2005, p.87).

\section{La autofiguración: concepto y constitutivos}

El término autofiguración se utilizó por primera vez en 1991 por la crítica argentina Sylvia Molloy (1996) y posteriormente fue recuperado por el también crítico argentino José Amícola, quien lo define, en una resignificación del término, como "Aquella forma de autorrepresentación que aparezca en los escritos autobiográficos de un autor, complementando, afianzando o recomponiendo la imagen propia que ese individuo ha llegado a labrarse dentro del ámbito en que su texto viene a insertarse" (Amícola, 2007, p.14).

Otro antecedente importante para establecer el concepto de "autofiguración" es la llamada "Filosofía de vida", propuesta por Wilhelm Dilthey (1833-1911), y el papel que dicha filosofía daba a la experiencia. Dilthey utilizó el término Selbstbesinnnung ("autognosis") para subrayar el modo de aprehensión de los hechos espirituales por parte del individuo (Ferrater, 1958, p. 362). 


\section{La cuestión del padre en el proceso de autofiguración}

Amícola establece una relación entre la figura del padre y el proceso de autofiguración en tanto que la idea de varones de la élite social del momento se apropia del mérito de poder contar su propia vida y construirse públicamente en este orden textual. De esta manera Amícola, siguiendo el estudio de Prieto, establece cómo en las autobiografías argentinas puede encontrarse el complejo de Edipo en casi todos los casos.

Freud (1986) había sostenido que cada niño elaboraba su complejo edípico, construyendo la figura de un padre "aristocrático". Así, según Freud, el niño está enamorado de la madre y tiene que apartar la figura del padre biológico para buscar un reemplazo del padre biológico, que fundamentalmente es un padre simbólico que además pertenece a la clase social aristócrata y así preservar a la madre (Freud, 1986).

Otra analista freudiana, Marthe Robert, retomará la misma idea para afirmar, además, que "la fabulación en el niño sobre sus orígenes paternos tiene que ver con su vergüenza de haber tenido un nacimiento bajo y de no ser nunca suficientemente amado" (Rober, 1972, p.46). Ahora, en esta fabulación de la vida, la madre también será encasillada dentro de una clase baja, de origen campesino, y este origen le permitirá al niño, en la fabulación, mantener consigo a la madre y colocar a la madre, al mismo tiempo, "a distancia de un padre fabulado y quimérico que le procuraría a él mismo un origen más noble" (Robert, 1972, p.50).

Para terminar de engarzar el concepto de autofiguración en la narrativa de Borges, habrá que tomar muy en cuenta sobre todo este último punto, puesto que servirá para establecer, al igual que la crítica hace con Rousseau, los mecanismos que hacen posible en Borges la autofiguración de sí mismo en la primera parte de su producción narrativa, la que tiene que ver con los relatos de cuchilleros, ya que, tal como señala la teoría freudiana, podemos encontrar esta separación materna y paterna en la narrativa del escritor argentino, identificando elementos en los relatos de cuchilleros con la figura de la madre y el padre en la representación de sí mismo. 


\section{La genealogía de Borges, lo político y lo autobiográfico}

Para fines prácticos se han tomado dos aristas para analizar la autofiguración borgeana, la primera, como se ha visto ya, tendrá que ver con la inserción, o, mejor dicho, la interpretación de Borges del canon literario, que derivará, como se mostrará más adelante, en la introducción de la gauchesca, literatura popular, dentro de la tradición occidental. La segunda arista tendrá que ver con el linaje familiar heroico y la reelaboración que el escritor hace de este linaje en los relatos de cuchilleros, especialmente en la adición de elementos que podrán relacionarse simbólicamente con la figura materna y paterna, respectivamente. De esta manera, al hacer el análisis se tomarán en cuenta estos dos elementos.

Se sabe que los antepasados de Borges "estaban entre los primeros europeos que llegaron a América" (Williamson, 2006, p.23). Entre sus antecesores más ilustres se encuentran, por ejemplo, Jerónimo de Cabrera, conquistador español, que fundó la ciudad de Córdoba en Tucumán, y también Juan de Garay, que fundó "el asentamiento del remoto poblado de Buenos Aires" (p.23).

Podemos encontrar en la producción literaria temprana de Borges esta afinidad entre lo político traducido en la esencia de lo nacional y lo autobiográfico. Ahora bien, los antepasados por los que el escritor argentino sentía predilección "eran los hombres que habían cortado vínculos con España y habían luchado para crear la nación argentina" (p.23). Como afirma Williamson, a pesar de que Borges siente una predilección por lo argentino, en su imagen pública de escritor se mostrará siempre crítico con el concepto de Estado-Nación y de la misma manera con el concepto de identidad nacional.

\section{Leonor Suárez, la madre}

La posición política de Borges se inclinará hacia el bando unitario, tanto por los lazos de sangre como por la propia convicción del escritor, y este sentimiento quedará vigente en la figura de la madre, que transmitirá en el hijo la filiación con los héroes del bando unitario y, por consiguiente, el 
desprecio hacia Rosas", "[Leonor Suárez] se identificaba con tanta fuerza con los héroes desposeídos de la familia que incluso de anciana se describía con orgullo a sí misma como una "salvaje unitaria", rechazando cualquier cosa que le recordara al tirano Rosas" (p.40).

Del mismo modo, curioso será también cómo Borges invierte estas relaciones de desprecio de la madre, es decir, retoma "gauchos, caudillos, las provincias [y] los usos y costumbres de las clases bajas" (p.40) y conforma así un universo propio, novedoso por esta mezcla entre lo culto y lo popular que será tan característico de su prosa. El influjo de la madre será decisivo para la consagración de algunos de los temas recurrentes en los cuentos de Borges, de temas y también de personajes, un ejemplo de esto será la provincia de Fray Ventos del Uruguay en el cuento de "Funes el memorioso", o un cochero de nombre Epifanio, cochero personal de Leonor Acevedo (2006).

\section{Jorge Guillermo Borges, el padre}

Los Borges tienen menos tradición que los Suárez, y muy probablemente descienden de Francisco Borges, un teniente de la armada portuguesa (Williamson, 2006). El abuelo de Borges, Francisco Borges, nació en Uruguay en 1833 (Williamson, 2006) y combatió durante la Batalla de Caseros.

Una característica fundamental en el tratamiento de la familia paterna es el hecho de que el abuelo paterno también participa activamente en la vida política de Argentina y termina uniéndose a la rebelión de Bartolomé Mitre, que trata de impedir la sucesión presidencial de Nicolás de Avellaneda, predilecto de Sarmiento. El coronel Borges termina sus días involucrado en la revuelta,

\footnotetext{
${ }^{2}$ Debe recordarse que el periodo en que nace Borges (1899) es especialmente problemático porque se está gestando en Argentina e Hispanoamérica un debate importante en cuanto a cómo se concibe la identidad, y, por lo tanto, la construcción del yo. Así, escritores de la talla de Esteban Echeverría o Domingo Faustino Sarmiento establecerán otro punto fundamental, el que tiene que ver con la civilización contrapuesta con la barbarie. En Borges esta dicotomía se manifiesta sobre todo en el lado materno, puesto que toda su familia, adepta al unitarismo y por tanto ferviente detractora del gobierno de Juan Manuel de Rosas, podría ser vista no desde la óptica de la civilización, es decir con el stablishment, con el orden sociopolítico imperante, sino con la barbarie, que en Argentina particularmente tiene al menos dos vertientes, la primera y más evidente es el gaucho, hombre nómada que vive en la llanura y no quiere ni pretende formar parte del Estado naciente, $y$, por otra parte, los grupos radicales que se forman y que terminarán por derrocar a Rosas para conformar la moderna Argentina, a fines del siglo XIX y principios del siglo XX. Para ahondar más en esta relación consultar Borges, una vida, del biógrafo Edwin Williamson, que ofrece un panorama amplio respecto a esta relación de la familia materna de Borges con el unitarismo y con la conformación del moderno Estado Argentino.
} 
durante la batalla de La verde, después de que dos proyectiles de bala lo alcanzan mientras está dando órdenes en el campo de batalla (Barrenechea, 1992, p.1005).

Debido a la muerte del coronel, su mujer y sus dos hijos se ven forzados a vivir de manera estrecha, Fanny Haslam termina convirtiéndose en profesora del Instituto de Lenguas Vivas, "convirtiéndose [...] en jefa del departamento de inglés" (Barrenchea, 1992, p.1005). En ese sentido, Jorge Guillermo nunca se identifica con lo argentino, más bien, lleva su herencia inglesa bien arraigada, y esta conciencia inglesa pasa posteriormente a Jorge Luis.

Finalmente, un hecho importante sobre la muerte del coronel Francisco es que su viuda se encarga de romantizar su muerte, y esta romantización pasa a su hijo y posteriormente a su nieto, que habría de encontrar aquí otro germen importante para habilitar la construcción de los relatos del culto al coraje. Ahora bien, este relato romantizado de la muerte tiene visos fantásticos, otro motivo que Borges recuperará después:

En esta versión [romantizada del relato] el general Mitre había ordenado a sus tropas que se retirasen del campo de batalla aun cuando el coronel Borges le informó que se habían quedado sin municiones. Cuando Mitre insistió en retirarse, Borges, que llevaba un poncho blanco, montó su corcel blanco y cabalgó hacia las líneas enemigas, con los brazos cruzados sobre el pecho. Cayó sobre una hondonada de balas y sus hombres lo llevaron sobre un cuero de vaca a una estancia vecina, donde murió por sus heridas. Se dice que sus últimas palabras fueron "He caído en la creencia de haber cumplido plenamente con mi deber y mis convicciones, y por los mismos principios por los que he luchado toda mi vida". (Vaccaro, 1996, p.22)

Muy probablemente en este relato romantizado existirá el germen de otra preocupación no menos borgeana, es decir, el hecho casi obsesivo de Borges por tratar de retener estos episodios familiares, de no dejarlos pasar, motivo por el cuál otra cuestión fundamental en la narrativa borgeana que es competente en la primera autofiguración del escritor argentino tiene que ver con los espacios y el tiempo histórico: 
Como han analizado diversos especialistas, en Borges hay una tendencia a idealizar el pasado argentino, especialmente las últimas décadas del siglo XIX y las primeras del XX; en su narrativa y en su poesía, el presente — de mediados de la década de 1920 en adelantesuele ser una degeneración de un pasado ilustre y heroico. (Dávila, 2018, p.10).

Queda claro que para Borges la ficcionalización del pasado heroico familiar dará pie a entablar el diálogo con su propia autofiguración, puesto que gran parte de la imagen que construye de sí mismo tiene bases importantes en estos antepasados. Lo interesante es ver cómo Borges da un giro al tratar episodios como el de Junín en el poema del mismo nombre, también es interesante que, al mismo tiempo, construye y se apropia de una imagen de Argentina que aparentemente no comparten ni la madre ni mucho menos el padre, así, podría pensarse que la inserción del gaucho en su producción literaria será acaso el modo en que Borges podría estar tratando de romper con esa herencia preconcebida que podría conjugarse con el tópico Civilización-Barbarie planteada por Echeverría, Sarmiento y José Hernández.

\section{Borges y los relatos de cuchilleros}

El primer relato publicado por Borges fue "Leyenda policial", publicado en 1927, en el número 38 de la Revista Martín Fierro. Posteriormente este relato fue recogido en El idioma de los argentinos con el título de "Hombres pelearon" (Dávila, 2018). Según autores como Jesús Dávila, ya en este relato se establecerán elementos constitutivos de la narrativa borgeana que serán constantes en los posteriores relatos de cuchilleros y que tienen que ver con los espacios y el tiempo histórico narrado (finales del siglo XIX, principios del siglo XX) (2018).

Otro rasgo importante señalado por Dávila respecto al tema del duelo y la gauchesca es que "el comportamiento - ambiguo e ilegal- de los personajes excluyen la participación de héroes impecables" (p.11). Importante será, en ese sentido, el hecho de que, mientras que en la narrativa borgeana se hace apología de estos personajes que representan impecablemente la marginalidad, en la poesía borgeana, estos temas no son recurrentes (2018). 
Otro rasgo que sí tienen "Leyenda policial", "Hombre de la esquina rosada" y relatos posteriores como "El desafío" es la "veneración atolondrada del compadrito", ya que en cuentos posteriores con el mismo tema esta característica "[se] cuestiona o, incluso, aniquila la admiración del cuchillero" (2018). Del mismo modo, otro texto capital para entender cómo se configurará la atmósfera de la pelea entre cuchilleros será "Evaristo Carriego" que, curiosamente, responde a una biografía del poeta argentino escrita, o más bien incluso ficcionalizada por Borges, y curioso será también cómo a partir de este texto Borges terminará de asentar el mundo posible de los relatos de cuchilleros, a los que volverá constantemente, y donde "Hombre de la esquina rosada" será "el primer regreso afortunado a ese mundo" (2018).

No debe confundirse el tratamiento que Borges da a los relatos de cuchilleros, porque Borges lo que hace es amalgamar temas vernáculos, temas populares, con este conocimiento de lo culto. En ese sentido, Borges entiende la importancia de la tradición oral en la gauchesca, que luego retoma en el modo de hablar de sus propios personajes:

Desde sus orígenes, el género en cuestión reúne a personas con formaciones muy distintas: por un lado, hay hombres con una cultura refinada para la época - por ejemplo, José Hernández y Eduardo Gutiérrez-; por otro, hombres analfabetos como solían ser los gauchos. El tratamiento de Borges de estos temas y su recepción favorable entre el público argentino forman parte de un largo proceso en el que convergen, no sin tensiones constantes, la cultura letrada y la cultura popular rioplatenses. $(2018$, p.14)

De esta manera, así como Borges es capaz de identificar la tradición de la literatura occidental, así también es capaz de identificar en la oralidad otro modo de tradición, motivo por el cual el plano del registro lingüístico, el cómo hablan sus personajes, será tal vez la manera en que Borges deja su marca muy particular que después será emulada por otros contemporáneos.

\section{Hombre de la esquina rosada, personajes, escenario, ambiente.}


Respecto a "Hombre de la esquina rosada" y la primera autofiguración de Borges en este cuento, habrá que rescatar lo dicho por Dávila respecto a cómo la biografía dudosa de Evaristo Carriego sirve como germen para desarrollar el relato de cuchilleros. Lo primero que vale la pena notar es el título, que proviene de un fragmento de la biografía de Carriego:

[...] el patio que es ocasión de serenidad, rosa para los días, el fuego humilde de San Juan, revolcándose como un perro en mitad de la calle, la estaca de la carbonería, su bloque de apretada tiniebla, sus muchos leños, la mampara de fierro del conventillo, los hombres de la esquina rosada. (Borges, citado en Dávila, 2018, p.22)

En "Evaristo Carriego", Borges desarrollará algunos elementos que posteriormente irá repitiendo en relatos tardíos como "El encuentro" (1969) "Historia de Rosendo Juárez" (1969), "Juan Muraña" (1970) y “El indigno" (1970) (Dávila, 2018) y que por supuesto ya son identificables en "Hombre de la esquina rosada". Estos elementos serán "el establecimiento nocturno, el arroyo Maldonado, el inmigrante y el guapo" (2018). De este modo en "Hombre..." la referencia del escenario donde suceden los acontecimientos se concatenará con los puntos señalados con anterioridad:

Los muchachos estábamos dende temprano en el salón de Julia, que era un galpón de chapas de cinc, entre el camino de Gauna y el Maldonado. Era un local que usté lo divisaba de lejos, por la luz que mandaba a la redonda el farol sinvergüenza, y por el barullo también" (Borges, citado por Dávila, 2018, p.23).

En el cuento serán relevantes, entre otras cuestiones, la relación que para Borges tendrá el tango con la vida nocturna y, de manera obvia, con los establecimientos clandestinos donde los personajes de "Hombre...", cuchilleros y prostitutas, participan en la descripción y en la trama:

Hacia los muchos corralones de la calle Cerviño o hacia los cañaverales y huecos del Maldonado -zona dejada con galpones de zinc, llamados diversamente salones, donde flameaba el tango, a diez centavos la pieza y la compañera- se trenzaba todavía el orilleraje y alguna cara de varón quedaba historiada, o amanecía con desdén un compadrito muerto con una puñalada humana en el vientre (Borges, citado por Dávila, 2018, p.23) 
Para entender en contexto cómo se relacionan los elementos señalados con anterioridad en la primera autofiguración borgeana habrá que añadir, además, el criterio del propio escritor argentino respecto a cómo entiende los elementos fundamentales en el modo de escribir relatos de cuchilleros que se encuentra ya desde "Hombres pelearon", donde Borges describe el culto al coraje:

Ésta es la relación de cómo se enfrentaron coraje en menesteres de cuchillo el Norte y el Sur. Hablo de cuando el arrabal, rosado de tapias, era también relampagueado de acero; de cuando las provocativas milongas levantaban en la punta el nombre de un barrio; de cuando las patrias chicas eran fervor. Hablo del noventa y seis o noventa y siete y el tiempo es caminata dura de desandar (Borges, citado por Dávila, 2018, p.17).

Lo que resalta, además de la figura del cuchillero, figura que se irá mitificando, y del culto al coraje, será también la configuración de un espacio al que Borges volverá constantemente en su obra (2018). Un recurso constante, como ya se ha mencionado, será el ambientar el tiempo de los hechos pero no de manera específica, un rasgo determinante tanto en "Hombre..." como en relatos de cuchilleros posteriores será, precisamente, esta indeterminación temporal, que situará los acontecimientos en algún punto de finales del siglo XIX y principios del siglo XX, y de hecho, quizá la única fecha específica que propone Borges aparece en "Leyenda policial", donde se establece una fecha mucho menos vaga: 1896 o 1897 (2018).

Desde que empieza a escribir relatos de cuchilleros, Borges ofrece una definición de las orillas: “Nadie dijo arrabal en esos antaños. La zona circular de pobreza que no era 'el centro' eran 'las orillas': palabra de orientación más despreciativa que topográfica” (Borges, citado por Dávila, 2018, p.18). Así mismo, este término no es invención del escritor, sino que recupera la palabra precisamente de finales del XIX, palabra que se empleaba para denominar despectivamente a los habitantes de los barrios pobres y limítrofes de Buenos Aires. 
Volviendo a la figura del cuchillero, se entiende que "La mayor obsesión del cuchillero suburbano es la fama: por ésta vive, mata y muere. No puede tolerar que otro lo supere en ese ámbito" (Dávila, 2018, p.18), y este será otro motivo que Borges aprovechará de continuo en su narrativa, porque siempre habrá una oposición entre el personaje principal y un contrincante directo que, en teoría, lo iguala o supera en fuerza y valor. En ese sentido, "Para que la 'liturgia' del duelo ocurra, debe haber dos guapos: uno va al barrio del otro a desafiarlo" (p.18), que es justo lo que sucede en "Hombre...".

Finalmente, el lenguaje será otro elemento fundamental de la relación entre relato y la autofiguración. Dávila señala que una de las características del lenguaje que emplea Borges es que utiliza formas arcaizantes para emular la voz de los cuchilleros:

No sólo el vocabulario puede dificultar la comprensión de este pasaje. En los relatos gauchesco-orilleros de Borges, suele haber un manejo "arcaizante" de la nomenclatura de las calles -lo que concuerda con la época en que las acciones se desarrollan-; es decir, se utilizan nombres antiguos. Además, se habla de sitios que con el paso de tiempo desaparecieron. (p.26)

En "Hombre...", el relato se centra en el duelo y posterior asesinato de un personaje apodado "el Corralero". Borges utilizará una forma de narrar específica a la que volverá en sus relatos tardíos. En "Hombre...", "Borges emplea un esquema narrativo que será recurrente en sus relatos gauchescoorilleros tardíos [...] un hombre de edad madura recuerda hechos de su niñez o de su juventud temprana" (p.29). De esta manera sabemos que el narrador que cuenta la historia aún es muy joven cuando conoce al Corralero la noche del asesinato (2018), y también podemos saber que aquel joven, que posteriormente asesinará al Corralero, tiene aspiración de convertirse también en gaucho, es decir, aspira a la fama que ser cuchillero le otorgará.

Otro elemento en relación con el lenguaje y con el narrador del cuento es la conciencia de la miseria, que se hace evidente mientras el personaje narra: "[...] pensé que yo era apenas otro yuyo de esas orillas, criado entre las flores de sapo y las osamentas. ¿Qué iba a salir de esa basura sino 
nosotros, gritones pero blandos para el castigo, boca y atropellada no más?" (Borges, citado por Dávila, 2018, p.29).

Ahora, el clímax de la historia en "Hombre..." tiene que ver con el hecho de que el Corralero, que llega a la zona como un guapo, le arrebata en la tangueada la mujer a Rosendo Juárez, el otro guapo, que debió de haber retado a duelo al Corralero y no lo hizo, malogrando así su honor y, por tal motivo, el narrador se siente obligado a asesinar al Corralero como un gesto casi heroico no tanto para devolverle el honor a Rosendo Juárez tanto como para probar su propio coraje. De esta manera, Dávila establece al menos tres motivos por los cuáles el narrador asesina al Corralero:

Podría decirse que el narrador asume la responsabilidad de matar al Corralero por tres motivos: la cobardía de Rosendo, las fanfarronadas del forastero y la posesión de la Lujanera; quizá esta última es la razón definitiva. El narrador no tolera la idea de que aquella mujer pase esa noche y muchas más al lado de Francisco. (2018, p.30)

Aquí encontramos un último móvil para el asesinato del Corralero, que tiene que ver con el deseo, y de esta manera, el juego del culto al coraje y la traición funciona desde dos perspectivas, el primero y más obvio entre el Corralero y Rosendo Juárez al despojarlo de la Lujanera en la tangueada, y el siguiente, que solo descubriremos al final, tiene que ver con que el narrador lleva a cabo el asesinato por la misma razón que el Corralero: el deseo. En el relato las intenciones del narrador se hacen evidentes precisamente por la omisión de un pasaje crucial para entender el orden de los hechos, pasaje donde sigue al Corralero y a la Lujanera fuera del salón de baile y, repentinamente, corta la historia y la dirige hacia otra parte. Así lo cuenta Dávila (2018):

"Muy lejos no podían estar. A lo mejor ya se estaban empleando los dos en cualesquier [sic] cuneta". Después de estas palabras, hay una brusca interrupción en el relato; el narrador empieza a hablar de su regreso al salón de Julia -luego de haber herido mortalmente a Francisco Real, como se nos revela al final del texto-: “Cuando alcancé a volver, seguía como si tal la cosa el bailongo". (p.30) 
Daniel Balderston (2013), teórico importante de la obra de Borges, afirma, sobre este relato y la serie de omisiones perpetradas por el narrador, que "el suceso fundamental del cuento no está narrado, apenas está sugerido" (pág. 8). Sobre este corte abrupto, el otro personaje que puede llenar el vacío de la narración es la propia Lujanera que, en un momento dado, casi al final del relato, vuelve al salón con el Corralero al borde de la muerte:

El hombre no estaba para esplicar. La Lujanera lo miraba como perdida, con los brazos colgando. Todos estaban preguntándose con la cara y ella consiguió hablar. Dijo que luego de salir con el Corralero, se jueron a un campito, y que en eso cae un desconocido y lo llama como desesperado a pelear y le infiere esa puñalada y que ella jura que no sabe quién es y que no es Rosendo. ¿Quién le iba a creer? (Borges, citado por Dávila, 2018, p.31)

Finalmente, el relato cierra con la confesión del propio narrador a Borges, que sólo hasta el final se muestra como el interlocutor al que se dirige prácticamente toda la historia:

Entonces, Borges, volví a sacar el cuchillo corto y filoso que yo sabía cargar aquí, en el chaleco, junto al sobaco izquierdo, y le pegué otra revisada despacio, y estaba como nuevo, inocente, y no quedaba ni un rastrito de sangre. (Borges, citado por Dávila, 2018, p.33).

Lo imprescindible del relato para compaginar todo lo anterior con la construcción de la figura del propio Borges es, precisamente, que aparezca nombrado el escritor argentino al final, y que se muestre además como interlocutor del otro, del cuchillero, del asesino, porque es a partir de este gesto que podemos empezar a dialogar entre autofiguración y texto.

José Amícola, en su definición de autofiguración, deja muy en claro que es imprescindible que entre autor y construcción textual se establezca una relación directa, en este caso la identidad nominal entre el Borges autor del relato y el Borges que en el plano ficcional escucha el relato. De esta manera se compagina el autor y su figura textual, ahora bien, un gesto decisivo en esta autofiguración es el hecho de que el propio Borges no participa activamente en el desarrollo de los acontecimientos, como se esperaría, por ejemplo, de antecesores como Echeverría o Sarmiento, que desde el momento en que toman la palabra van construyendo una imagen de sí mismos a 
través de sus experiencias vivenciales y, en menor medida, de su relación intelectual con otros textos. Otro punto fundamental en el caso de Sarmiento es cómo asimila estas lecturas y construye una imagen de sí mismo basada en modelos literarios diversos, ya que a pesar de los usos y costumbres propios de un hombre que no ha salido de América Latina se suman los modos de ser europeos, occidentales, creando una amalgama muy particular entre autor y autofiguración.

Adolfo Prieto, teórico especializado en el género autobiográfico en el Río de la Plata, establecerá esta relación, en los años 60, acerca de cómo los autobiógrafos argentinos más famosos hacen tendencia en cuanto a construir una imagen pública de sí mismos, herencia directa de Rousseau, y cómo esta imagen construida tiene intenciones políticas bien definidas. Prieto estudia dos textos autobiográficos de Sarmiento sobre los cuáles empieza a construir su teoría. Los dos textos que analiza Prieto son "Mi defensa" (1843) y "Recuerdos de provincia” (1850) que, según él, se muestran como "obras complementarias, donde la segunda es el corolario de la primera" (Pietro, 1966). Respecto a la primera, Sarmiento la escribe desde el exilio, en Chile, y a pesar de que es relativamente joven (tiene 32 años al momento de su publicación), ya tiene herramientas discursivas para "hacer una suma de lo vivido a causa de las vicisitudes políticas experimentadas" (Prieto, 1966).

Esta relación más histórica que literaria entre Sarmiento y Borges tendrá que ver, precisamente, con la negativa del propio Borges a aceptar sin más el modelo escritural de la época, y por tal motivo su autofiguración en "Hombre..." bien podría tratar de cuestionar estos modelos heredados, ya que otro punto importante a considerar es cómo el propio Borges, que conoce a profundidad, como ya se ha dicho, la tradición literaria en Argentina, no aceptará inocentemente el modelo autobiográfico tradicional, más bien, y esta será una constante en toda su obra narrativa, tratará de establecer unas pautas individuales para construir su propia imagen de autor.

La única relación palpable entre la autobiografía del Río de La Plata y la autofiguración borgeana es el tópico de la biblioteca y la relación de la figura de autor con su ideario intelectual heredado por la tradición literaria, aunque, como se ha dicho anteriormente también, esta relación 
no es evidente en "Hombre..." y solo puede deducirse por la actitud del Borges ficcional, que se limita a escuchar el relato, que no participa en la trama.

Finalmente habrá que establecer otra relación, ahora en cuanto a la herencia, el propio árbol genealógico del escritor argentino. Si bien Amícola acepta lecturas simbólicas, en este caso, psicoanalíticas, al momento de reconstruir la imagen del yo autofigurado, en el caso de Borges no sería extraño encontrar elementos que hagan evidentes este análisis.

El caso de Borges resulta paradigmático porque, como es bien sabido, una de las características en su producción es la ausencia de experiencias vivenciales, que reemplaza con la figura y el símbolo de la propia biblioteca. Si bien es cierto que en este texto en particular la concepción de la biblioteca no está expresada, lo está la actitud de la autofiguración del Borges que escucha la historia, y en ese sentido, del Borges que cede la palabra.

En cuanto a la identificación de elementos relacionados con el padre y la madre en la narrativa del escritor argentino, la propia teoría freudiana ofrece, como es bien sabido, una relación de corte edípico, que el propio Amícola acepta cuando empieza a cuestionar el rol de la autofiguración masculina en las autobiografías del Río de La Plata. Amícola establece una relación entre la figura del padre y el proceso de autofiguración en tanto que la idea de varones de la élite social del momento se apropia del mérito de poder contar su propia vida y construirse públicamente en este orden textual. De esta manera Amícola, siguiendo el estudio de Prieto, establece a las claras cómo en las autobiografías argentinas puede encontrarse el complejo de Edipo en casi todos los casos.

En la teoría freudiana, Freud (1986) había sostenido que cada niño elaboraba su complejo edípico, construyendo la figura de un padre "aristocrático". Así, según Freud, el niño está enamorado de la madre y tiene que apartar la figura del padre biológico para buscar un reemplazo del padre biológico, que fundamentalmente es un padre simbólico que además pertenece a la clase social aristócrata y así preservar a la madre (Freud, 1986). Otra analista freudiana, Marthe Robert (1972), retomará la misma idea para afirmar, además, que "la fabulación en el niño sobre sus orígenes paternos tiene que ver con su vergüenza de haber tenido un nacimiento bajo y de no ser 
nunca suficientemente amado" (p.46). En esta fabulación de la vida, la madre también será encasillada dentro de una clase baja, de origen campesino, y este origen le permitirá al niño, en la fabulación, mantener consigo a la madre y colocar a la madre, al mismo tiempo, "a distancia de un padre fabulado y quimérico que le procuraría a él mismo un origen más noble" (Robert, 1972, p.50).

La explicación de Robert tendría sentido en "Hombre..." tomando en cuenta que, si se puede establecer un balance entre lo materno y lo paterno en la obra del escritor argentino, lo materno estaría fuertemente influido en la gauchesca, esto por la actitud de la propia madre a sentirse identificada con lo argentino desde muy niña, por ejemplo, en un episodio donde la madre de Leonor, al darse cuenta de la timidez de su hija, "le consiguió una niña india llamada Dominga como compañera de Juegos" (Williamson, 2006, p.39-40) o en un episodio similar, gustaba de escuchar las historias del pasado heroico de la familia en las noches, antes de dormir (Williamson, 2006).

De esta manera, la idea del duelo no es tanto literal como simbólica, puesto que a pesar de que Leonor no sentía especial interés en la figura del gaucho, el hecho de haber sido una mujer brillante que había sido sometida por las costumbres de la época a una vida casi servil podría contrastar con su actitud rebelde, desajustada, de respetar los cánones de la época y, en ese sentido, luchar silenciosamente con estos modelos impuestos, además, por supuesto de sentirse plenamente identificada con lo argentino y lo marginal, al considerarse ella misma como "una sucia y salvaje unitaria" (Williamson, 2006) cuando se le preguntaba sobre sus orígenes y su filiación política. De este modo, no es difícil entrever en "Hombre..." estos guiños discretos donde la imagen de la madre puede relacionarse con la idea del duelo (no literal), con lo marginal, etc.

El reflejo de lo paterno en la narrativa de Borges estaría, caso contrario, ligado más bien a la idea de la biblioteca, del saber libresco e incluso podría también relacionarse con la propia falta de experiencias vitales del propio Borges, con la timidez y la vacilación. Otra cuestión de suma importancia es que lo paterno podría aparecer quizá en la propia autofiguración del escritor argentino, en ese guiño que el narrador hace al nombrarlo al final del relato, porque recordemos que, a diferencia de la madre, el padre de Borges nunca siente una plena identificación con lo argentino, e incluso cuando trata de identificarse con la muerte del padre, el coronel, tiende a 
mostrarse indeciso y vacilante, actitud que heredará a su hijo Jorge Luis y que podrá hacerse evidente en "Hombre..." en el hecho inmediato de nunca tomar la palabra en el relato:

El efecto sobre Jorge Guillermo de esta glorificación del coronel Borges fue hacerlo dudar de su propio valor. El muchacho creció bajo la imagen opresiva de un padre al que nunca había conocido y a quien no podría haber conocido nunca sino de modo indirecto, a través de la madre. Tiene que haber sido imposible para él, en consecuencia, cuestionar, por no hablar de rebelarse, contra ese padre mítico sin experimentar un fuerte sentimiento de culpa. (Williamson, 2006, p.48)

De esta manera podemos entrever que, los relatos de cuchilleros, con los elementos señalados con anterioridad, estarían ligados íntimamente a la madre, es decir, desde el escenario, el duelo y lo costumbrista, y la figura del propio Borges estaría ya más relacionada con esta actitud de vacilación, esta herencia del carácter del padre que se hará constante en prácticamente toda la narrativa posterior de Borges donde el propio escritor aparezca autofigurado. Así, relatos posteriores como "El sur", "Tlön, Uqbar Orbis Tertius" o “El Aleph” tendrán en común esta autofiguración del escritor argentino, un hombre tímido que relaciona sus experiencias de vida con el tópico de la biblioteca o la propia tradición. Un último punto por recalcar es que, probablemente, en la línea paterna, el canon y la tradición literaria europea será una constante en el modo de narrar, y por ese mismo motivo los relatos de cuchilleros, relacionados con el color local, con lo nacional, serían una excepción importante que recordarán a la madre.

\section{Conclusión}

A modo de conclusión habrá que decir también que la autofiguración de Borges, que trata de romper este yo "absoluto" heredado por Rousseau y emulado ampliamente en Argentina durante prácticamente todo el siglo XIX y la primera mitad del siglo XX, retoma principios clásicos en la construcción del yo, específicamente hablando de los casos de Grecia y Roma, donde la comunidad determinaba la constitución del sujeto como un todo, como una colectividad. De esta manera, 
teóricos como Bajtín establecerán una diferencia importante entre el yo público y el yo privado: De lo anterior puede desprenderse que el hombre público era lo que predominaba en la época clásica, entendiéndose entonces que no se podía concebir otra configuración que no fuera ésta (Amícola, 2007, p.21) Por lo tanto “En el mundo clásico vivir era, así, vivir en función de los otros [...], vivir dentro de una comunidad. Esta concepción de la vida no permitía pensar que existiera la penuria a solas ni la reflexión introvertida" (Bajtín, 1975, p. 281-283).

Quizá por esta razón Borges, en un giro inesperado, lejos de una pretensión individual en la construcción de su yo privado, quiere volver a la idea de comunidad cediendo la palabra. Tal vez este será uno de los motivos principales de jugar con su propia autofiguración en su narrativa más temprana, y continuar explotando este recurso prácticamente en toda su obra posterior, con la diferencia de que en autorrepresentaciones textuales posteriores sí podríamos ver una participación más activa, que estaría también ligada a su periodo más conocido, el que tiene que ver con la publicación de Ficciones.

Otro aspecto, el relacionado con la lectura freudiana admitida por Amícola, no se vería tal cual de manera completa en "Hombre...", aunque, cuando Roberts habla de la suplantación del padre no es difícil pensar en tutores intelectuales que el escritor argentino adoptó desde su juventud más temprana. Nos referimos, en este caso, al escritor español Rafael Cassinos-Assens, que incluso comentó los primeros ocho libros publicados de Borges y no solo eso, sino que reiteradamente el escritor argentino, en entrevistas, habló abiertamente de la influencia del escritor judeoespañol en su obra (Cajero, 2015, p. 11) y también al escritor argentino Macedonio Fernández. Si bien cuando se habla de esta búsqueda de un padre figurado nos remitimos estos dos ejemplos, la relación no estaría resuelta en el relato de "Hombre...", y más allá de pensar que la figura del padre tiene que ser sometida o borrada en este juego edípico, en Borges podemos ver, no obstante, que quizá de manera sistemática le otorga valores y lugares diferentes en su narrativa tanto a la figura del padre como a la figura de la madre, estableciendo un vínculo realmente especial y único en su proceso de autofiguración. 


\section{Referencias}

Amícola, J. (2007). Autobiografía como autofiguración: estrategias discursivas del yo y cuestiones de género. Rosario: Beatriz Viterbo Editora.

Bajtín, M. (1975). Esthétique et théorie du roman (trad. de Daria Olivier). París: Gallimard.

Balderston, D. (2013). "Puntos suspensivos": sobre o manuscrito de "Hombre de la esquina rosada". Manuscrítica. Revista de crítica genética, (24), 7-14. Recuperado el 13 de abril de 2020, de https://www.borges.pitt.edu/sites/default/files/Balderston_0.pdf

Barrenechea, A. M. (1992). Jorge Luis Borges y la ambivalente mitificación de su abuelo paterno.

Nueva revista de Filología Hispánica, 40(2), 1005-10024.

Bordieu, P. (2005). La ilusión biográfica. Archipiélagos, (69), 87-93.

Bruss, E. (1976). Autobiographical Acts. The changing situation of a literary genre.

Baltimore/Londres: John Hopkins University Press.

Cajero, A. (2015). El maestro y el discípulo. Rafael Cassinos- Assens, lector del joven Borges, ensayista. En R. Olea Franco (Ed.), El legado de Borges (pág. 11). México: El colegio de México.

Dávila, J. (2018). Las posibilidades de una tradición literaria: configuración y reconfiguración del relato gauchesco-orillero en Borges (tesis doctoral). El Colegio de México, Ciudad de México.

Ferrater, J. (1958). Diccionario de Filosofía. Buenos Aires: Sudamericana.

Freud, S. (1986). Obras completas. Volúmen 9 (1906-08). Buenos Aires: Amorroru. Recuperado el 9 de junio de 2020, de https://www.bibliopsi.org/docs/freud/09\%20-\%20Tomo\%20IX.pdf

Lejeune, P. (2005). Signes de vie. Le pacte autobiograpique. Paris: du Seuil.

Molloy, S. (1996). Acto de presencia. La escritura autobiográfica en Hispanoamérica. México: Fondo de Cultura Económica.

Olney, J. (1980). Autobiography. Essays Theoretical and critical. Princeton: Princeton University Press.

Prieto, A. (1966). La literatura autobiográfica en Argentina. Buenos Aires: Centro Editor de América Latina. 
Robert, M. (1972). Roman des origines et origines du roman. París: Gallimard.

Starobinski, J. (1971). Jean-Jacques Rousseau. La transparence et l'obstacle, suivi de sept essais sur Rousseau. París: Gallimard.

Sturrock, J. (1993). The language of Autobiography. Studies in the First Person Singular. Cambridge: Cambridge University Press.

Vaccaro, A. (1996). Georgie (1899-1930): una vida de Jorge Luis Borges. Buenos Aires: Proa/Alberto Casares.

Williamson, E. (2006). Borges, una vida. Buenos Aires: Seix Barral. 